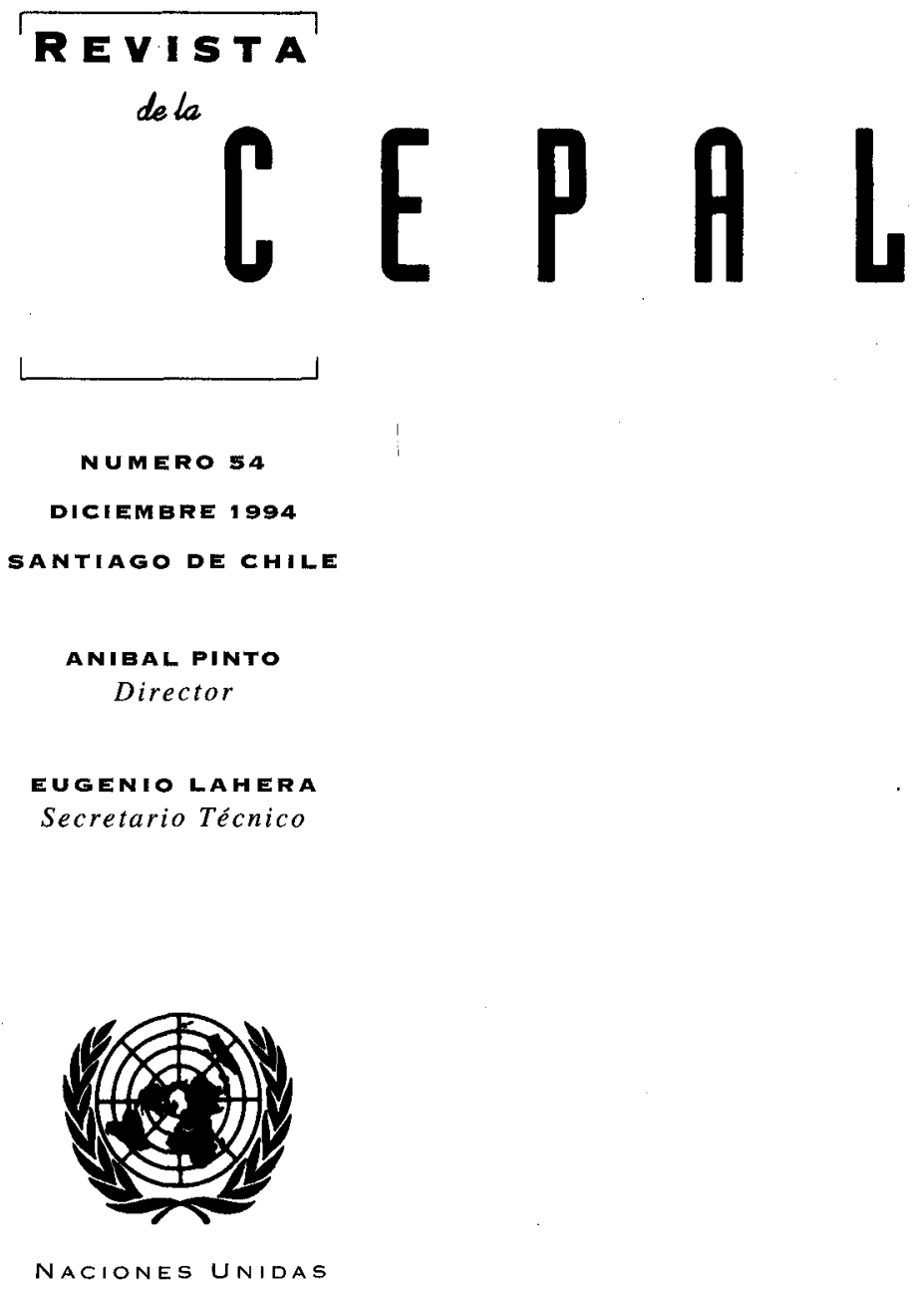


Mercados de salud: morfología, comportamiento y regulación

Jorge Katz y Ernesto Miranda

¿Liberalización o desarrollo financiero?

Günther Held

Ajuste fiscal y gasto social

Rossella Cominetti

Logros y obstáculos en la educación formal de las mujeres

Diane Alméras

¿Qué se entiende por flexibilidad del mercado de trabajo?

Ricardo A. Lagos

Modernización de la supervisión bancaria

Christian Larraín

Costos y beneficios de la integración centroamericana

Luis Cáceres

Algunas enseñanzas de las privatizaciones en Argentina

Daniel Azpiazu y Adolfo Vispo

Ventajas comparativas extraordinarias y crecimiento a largo plazo:

el caso de Ecuador

André A. Hofman y Rudolf Buitelaar

Industria cultural y nuevos códigos de modernidad

Martín Hopenhayn

Orientaciones para los colaboradores de la Revista de la CEPAL

Publicaciones recientes de la CEPAL 


\section{Ventajas comparativas extraordinarias y crecimiento a largo plazo: el caso de Ecuador}

\section{André A. Hofman Rudolf M. Buitelaar \\ Los autores son oficiales de asuntos económicos de la División de Desarrollo Económico de la CEPAL en Santiago de Chile y de la Sede Subregional de la CEPAL en México, respectivamente.}

El presente artículo tiene por objeto describir cómo se está llevando a cabo en Ecuador la transformación del régimen comercial y de industrialización y cuáles son los factores sistémicos que condicionan su realización. Una perspectiva de largo plazo de la política y el crecimiento económicos de ese país (si se considera todo el siglo $\mathrm{XX}$ ) revela que el crecimiento ha sido relativamente rápido comparado con el de otros países de la región, y que las exportaciones han sido su fuerza motriz. Lo inquietante es que estas exportaciones han estado dominadas por el auge de unos pocos productos en distintas épocas y que, por lo tanto, ese crecimiento ha mostrado un definido carácter intermitente. El comportamiento empresarial parecería caracterizarse por una propensión a la obtención de rentas espurias, ya que los ingresos económicos naturales han estado presentes en varias épocas de la historia. En el artículo se desarrolla la hipótesis de que uno de esos factores sistémicos es el crecimiento inestable atribuible en parte a la existencia de ventajas comparativas extraordinarias y se muestran los efectos del auge y la caída de las exportaciones bajo diferentes regímenes normativos. La conclusión general es que la política de sustitución de importaciones creó una industria manufacturera que era apenas competitiva, principalmente porque sustituía los ingresos económicos provenientes de utilidades imprevistas por ingresos económicos inducidos por políticas. En la sección final se analizan los lineamientos de un planteamiento de política que minimiza los efectos nocivos de la existencia de ingresos espurios. 


\section{I}

\section{Introducción}

Ecuador, como la mayoría de los países de América Latina, sufrió una de las crisis económicas más agudas en los años ochenta, con inflación creciente y crecimiento per cápita negativo, la que condujo a un cambio sustancial de las políticas económicas. Existe también en Ecuador, como en la mayor parte del resto de los países de la región, la convicción creciente de que hay que desmantelar la estrategia de industrialización basada en la sustitución de importaciones, y reorientar la economía hacia una estrategia de desarrollo más abierta al exterior. Este cambio de política se advierte claramente al examinar los programas gubernamentales de las dos administraciones anteriores y de la actual, pero los programas que se han introducido, de carácter más ortodoxo o heterodoxo, han fracasado debido a desastres naturales o a factores sistémicos políticos y económicos. Este artículo tiene por objeto describir cómo se está llevando a cabo esta transformación del régimen comercial y de industrialización y cuáles son los factores sistémicos que condicionan su realización. En él se desarrolla la hipótesis de que uno de esos factores sistémicos es el crecimiento inestable del Ecuador que puede atribuirse en parte a la existencia de ventajas comparativas extraordinarias y se muestran los efectos del auge y la caída de las exportaciones bajo diferentes regímenes normativos.

En Ecuador los planteamientos de política para diversificar la base exportadora y mejorar, por ende, la estabilidad del crecimiento económico tienen un largo historial rara vez exitoso. Tal vez sólo durante el apogeo de la bonanza petrolera, a mediados de los años setenta, pueda observarse un repunte notorio de las exportaciones no tradicionales. Esto hace que paradójicamente el período 1973-1978, sumado a los años de la segunda guerra mundial, sea el único en que los efectos conocidos de la "enfermedad holandesa" sean menos visibles en el desempeño de otros bienes comerciables. Pero estos hechos estuvieron vinculados también con un comportamiento caracterizado por la obtención de rentas espurias (rent-seeking) mientras se ideaban diferentes instrumentos normativos para canalizar los ingresos petroleros hacia la industria manufacturera. El colapso de comienzos de los años ochenta demostró lo in- sostenible de este impulso exportador basado en los ingresos petroleros.

Una perspectiva de largo plazo de la política y el crecimiento económicos del Ecuador (considerando todo el siglo XX) revela que el crecimiento ha sido relativamente rápido comparado con el de otros países de la región, y que las exportaciones han sido su fuerza motriz. Lo inquietante es que estas exportaciones han estado dominadas por el auge de unos pocos productos en distintas épocas y que, por lo tanto, el crecimiento ha mostrado una definida característica intermitente. El comportamiento empresarial parecería caracterizarse por la obtención de rentas espurias, ya que los ingresos económicos naturales han estado presentes en varios momentos de la historia.

Los distintos enfoques parecen estar cerrando un círculo: el régimen centrado en el laissez faire de comienzos de siglo fue abandonado durante la gran depresión de los años treinta, y la estrategia intervencionista posterior de la sustitución de importaciones se empezó a desmantelar durante la crisis de la deuda de los años ochenta. Lo que ahora se debate es si el libre juego de las fuerzas del mercado conducirá al país a un mejor desempeño, o si se debe diseñar un enfoque normativo distinto y qué implicaría esto.

No queda claro por qué el desmantelamiento de las políticas intervencionistas conseguiría per se un crecimiento elevado y estable. El país sigue dependiendo de las exportaciones basadas en notables ventajas naturales, lo que torna inestable el crecimiento a largo plazo y conduce a lo que se ha dado en llamar el crecimiento "ultrasesgado". Hay razones poderosas para apoyar el desmantelamiento de la mayoría de las políticas centradas en la sustitución de importaciones, así como también las hay para sugerir que se precisa un tipo diferente de intervención en el mecanismo de mercado. Las lecciones que se desprenden de los planteamientos de política ecuatorianos pueden arrojar luz sobre cómo perfilar una nueva estrategia, uno de cuyos aspectos principales es cómo evitar que las empresas manufactureras procuren obtener rentas espurias.

En las secciones siguientes se desarrolla el argumento en forma descriptiva y cronológica. En la segunda sección se ilustra el problema del crecimiento inestable mediante series cronológicas que abarcan gran 
parte del siglo $\mathrm{XX}$ y se establece una comparación internacional. En la tercera sección se postula la hipótesis de que este problema puede atribuirse a la presencia de ventajas comparativas extraordinarias, que provocan los efectos de la "enfermedad holandesa".

La cuarta sección se vale de la construcción de series cronológicas de largo plazo de las exportaciones y los tipos de cambio efectivos reales para ilustrar los efectos del auge y la caída exportadores bajo diferentes regímenes normativos. Hay tres observaciones decisivas para avalar el argumento: la primera es que un auge exportador en un régimen de laissez faire impide en efecto el desarrollo de otros bienes comerciables; la segunda es que una caída de las exportaciones provoca cambios del régimen normativo; y la tercera es que la política de sustitución de importaciones diseñada para modificar los efectos del auge exportador, estimuló el repunte de otros bienes comerciables, pero no logró ofrecer una base sostenible para diversificar las exportaciones y estabilizar el crecimiento.

Para explicar sobre todo la tercera observación, en la quinta sección se analizan con cierto detalle los enfoques de política y en la sexta el comportamiento de las empresas en diferentes etapas del ciclo augecaída. La conclusión general es que la política de sustitución de importaciones creó una industria manufacturera que era apenas competitiva, sobre todo porque sustituía los ingresos económicos provenientes de utilidades imprevistas por ingresos económicos inducidos por políticas. En la séptima y última sección se analizan los lineamientos de política que minimizan los efectos nocivos de la existencia de ingresos espurios y se presentan una síntesis y las conclusiones del trabajo.

\section{II}

\section{El problema fundamental: la inestabilidad del crecimiento económico y la}

\section{productividad a largo plazo}

El período 1900-1989 se ha subdividido como se ilustra en los cuadros 1 y 2 a fin de posibilitar las comparaciones internacionales (Maddison, 1986 y 1991 y Hofman, 1993a). Por cierto, cuando se trata de un país en particular estos puntos de referencia son demasiado rígidos, por lo que en el caso ecuatoriano daremos las etapas apropiadas, cuando proceda. Sin embargo, cabe señalar que nuestras etapas calzan bastante bien con el desarrollo económico de este país (Benalcazar, 1989, y Hofman, 1994).

Los primeros años del siglo XX muestran un rápido crecimiento, impulsado principalmente por las exportaciones de cacao (especialmente, entre 1908 y 1914) (Moncada, 1991, y Salgado, 1989). En la etapa comprendida entre 1914 y 1924 el crecimiento fue relativamente lento debido, entre otras cosas, a la primera guerra mundial y la disminución de las exportaciones de cacao. En el segundo lustro de los años veinte las tasas de crecimiento mejoraron luego de reformas institucionales (la creación del Banco Central) y políticas orientadas al desarrollo y el fomento de las exportaciones (Drake, 1984, Rodríguez, 1987 y Marchán Romero (comp.), 1987).
La "Gran Depresión" terminó con esta fase promisoria y sumió al Ecuador, junto con América Latina y el resto del mundo, en un período recesivo. Hemos dividido este último en dos subperíodos — 1929-1938 y 1938-1950 - ya que ambos muestran resultados muy diferentes a escala mundial. El primero, 1929-1938, mostró una desaceleración a escala mundial del crecimiento per cápita. Este panorama cambió radicalmente en el segundo, 1938-1950, cuando el mundo sufrió el desastre de la segunda guerra mundial y América Latina, relativamente intacta, aumentó sus exportaciones e inició un proceso de industrialización basado en la sustitución de importaciones inducido también por la no disponibilidad de importaciones, lo que fomentó el crecimiento económico (Blomström y Meller, 1990, y Abril-Ojeda, 1990).

Las tasas de crecimiento per cápita entre 1950 y 1989 (cuadro 1), indican una aceleración del mismo en Ecuador y América Latina durante el período 1950-1980, y una desaceleración extrema, incluso con un crecimiento per cápita negativo, en los años ochenta. El panorama es distinto para los países asiáticos y los países adelantados que muestran una ace- 
leración del crecimiento mucho mayor entre 1950 y 1973; pero los primeros siguieron creciendo incluso un poco más entre 1973 y 1980 y volvieron a hacerlo entre 1980 y 1989 , en tanto que los segundos desaceleraron abruptamente su crecimiento entre 1973 y 1980 y mostraron sólo una leve aceleración en los años ochenta.

En el cuadro 2 se comparan los distintos niveles de PIB per cápita con el de los Estados Unidos para el período 1900-1989.

Por tanto, resulta claro que el historial del crecimiento del Ecuador en una perspectiva comparada es bastante satisfactorio. No obstante, un estudio más detenido revela algunos inconvenientes importantes. En el gráfico 1 figuran datos sobre el crecimiento anual del PIB per cápita expresado en dólares constantes entre 1940 y 1990 . A primera vista el registro del crecimiento es algo inestable. El crecimiento para todo el período de 50 años alcanza en promedio a $2.5 \%$ anual, pero la desviación estándar es de $4.7 \%$. En los años cuarenta, setenta y ochenta las tasas de crecimiento oscilan entre 8 y $10 \%$ anual, o son negativas.
Este crecimiento inestable puede relacionarse con el desempeño de las exportaciones, como sostendremos en el párrafo siguiente, más teórico. Las exportaciones totales per cápita en dólares constantes durante ese mismo período de 50 años muestran una tasa de crecimiento promedio superior a $7 \%$ anual, pero con una desviación estándar de $26 \%$. Es decir, las tasas de crecimiento anuales han llegado a elevarse hasta $80 \%$ o más, y también han caído a $-20 \%$ o menos.

Otras fallas del desempeño del crecimiento a largo plazo más bien favorable del Ecuador se refieren al crecimiento de la productividad, y concretamente a la densidad de capital de dicho crecimiento y a la calidad de la mano de obra. En un artículo de Hofman (1993b), que trata de la productividad del empleo en Ecuador y los países latinoamericanos, se muestra que en el primero (salvo entre 1929 y 1938) las tasas de crecimiento son sistemática y significativamente superiores a las de los últimos. En cuanto a la productividad del capital el cuadro general es algo distinto ya que Ecuador tenía a este respecto un crecimiento menor entre 1950 y 1989 que el

CUADRO 1

Producto interno bruto per cápita, 1900-1989.

(Tasas medias anuales de crecimiento)

\begin{tabular}{lccccccc}
\hline País/región & $1900-1913$ & $1913-1929$ & $1929-1950$ & $1950-1973$ & $1973-1980$ & $1980-1989$ & $1900-1989$ \\
\hline Ecuador & 2.5 & 1.6 & 2.0 & 2.9 & 3.3 & -0.7 & 2.2 \\
América Latina & 1.9 & 1.6 & 1.7 & 2.5 & 2.3 & -0.6 & 1.7 \\
Países asiáticos & 0.5 & 1.0 & -0.6 & 4.8 & 5.4 & 5.9 & 2.3 \\
Península Ibérica & 1.1 & 0.7 & 0.4 & 5.3 & 1.4 & 1.9 & 2.1 \\
Países adelantados & 1.2 & 1.5 & 0.5 & 4.7 & 1.8 & 2.1 & 2.1 \\
Estados Unidos de América & 2.0 & 1.7 & 1.5 & 2.2 & 1.0 & 2.2 & 1.8 \\
\hline
\end{tabular}

Fuente: A.A. Hofman, 1993b.

CUADRO 2

Producto interno bruto per cápita, 1900-1989

(Estados Unidos de América $=100$ )

\begin{tabular}{lrrrrrrr}
\hline País/región & 1900 & 1913 & 1929 & 1950 & 1973 & 1980 & 1989 \\
\hline Ecuador & 12 & 13 & 13 & 16 & 19 & 22 & 17 \\
América Latina (promedio) & 29 & 29 & 28 & 28 & 29 & 32 & 24 \\
Países asiáticos & 18 & 15 & 14 & 9 & 16 & 22 & 26 \\
Península Ibérica & 34 & 31 & 28 & 21 & 41 & 42 & 40 \\
Países adelantados & 60 & 54 & 51 & 43 & 68 & 71 & 70 \\
Estados Unidos de América & 100 & 100 & 100 & 100 & 100 & 100 & 100 \\
\hline
\end{tabular}

Fuente: A.A. Hofman, 1993 b. 
GRÁFICO

\section{Ecuador: Tasas de crecimiento per cápita,} 1940-1990

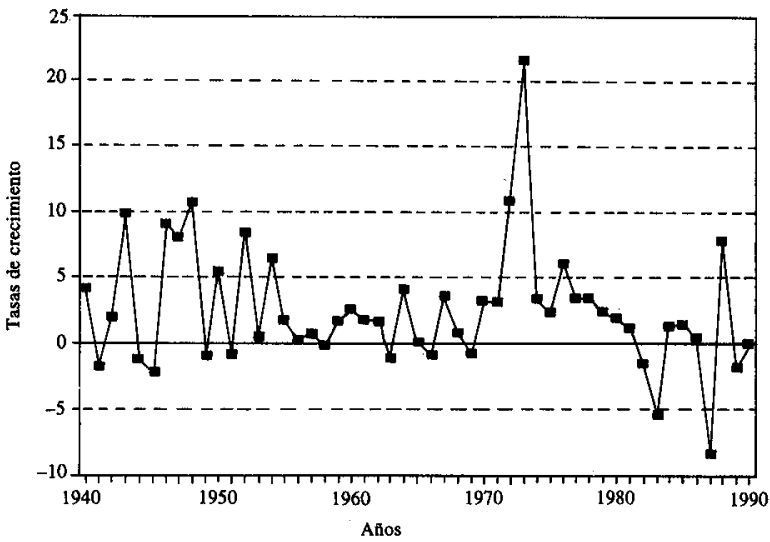

promedio de los países latinoamericanos. En cuanto a la productividad total de los factores Ecuador tenía un buen desempeño, pues registraba el mayor crecimiento junto con Colombia. Por lo que se refiere a los insumos laborales, se observa que la tasa de crecimiento de la calidad de la mano de obra es muy inferior a los estándares de otras economías en desarrollo.

En suma, el historial de crecimiento del Ecuador en este siglo ha sido favorable dentro de una perspectiva comparativa, pero con los problemas de una gran inestabilidad. El desencadenante de esta situación sería el desempeño global muy inestable, pero no obstante dinámico, de las exportaciones. Otros problemas vinculados con el desempeño del crecimiento ecuatoriano son la densidad de capital del crecimiento y la lenta mejoría de la calidad de la mano de obra.

\section{III}

\section{La hipótesis: la "enfermedad holandesa" conduce al crecimiento inestable}

Desde que la revista The Economist acuñó la expresión "enfermedad holandesa", al referirse a los problemas de la economía holandesa como consecuencia del alza del gas natural luego de la primera crisis petrolera, ésta se ha asociado casi siempre con la situación existente en los países exportadores de petróleo. Empero, conceptualmente puede aplicarse (y se ha aplicado) a toda suerte de grandes utilidades imprevistas que obtiene una economía. En Bianchi y Nohara (1988), el concepto de ventaja comparativa extraordinaria se utiliza como sustituto de "enfermedad holandesa", y se aplica a la experiencia del desarrollo histórico de América Latina con el que calza muy bien. Seguiremos aquí su argumentación a fin de identificar los efectos que rastrearemos en toda la experiencia del desarrollo ecuatoriano.

La hipótesis medular postula que la explotación irrestricta de los ingresos económicos crea distorsiones que favorecen tanto a los sectores con ventajas competitivas extraordinarias como a los sectores de bienes no comerciables, e impide la producción de otros bienes comerciables. Esta hipótesis se basa en un argumento estático y otro dinámico. $\mathrm{El}$ argumento estático sostiene que un auge exportador modifica los precios relativos a favor de un bien comerciable en auge, lo que tiene un impacto similar a un impuesto general sobre los demás bienes comerciables. El mecanismo funciona como sigue: la afluencia masiva de divisas provoca un aumento brusco de la demanda interna. Esto ejerce una presión inflacionaria sobre los bienes no comerciables, suponiendo que el crecimiento de la producción de estos bienes no podrá igualar al de la demanda. La fuerte inversión pública en bienes no comerciables (infraestructura, servicios públicos) exacerba estas presiones inflacionarias en el corto plazo, ya que debe transcurrir un tiempo considerable antes de que aumente la producción. Los precios de los bienes comerciables se controlan mediante el aumento de las importaciones. Los tipos de cambio se apreciarán menos que la tasa de inflación interna, y se apreciará el tipo de cambio efectivo real. Se produce así una pérdida de competitividad, que impide el crecimiento de otros bienes comerciables y erosiona la ventaja comparativa del bien comerciable en auge. Por ende, el movimiento del tipo de cambio efectivo real es fundamental en estos mecanismos, y aunque no constituye la única explicación, en la próxima sección se utilizará el índice del tipo de cambio efectivo real para ilustrar la incidencia de los efectos de la "enfermedad holandesa" 
El argumento dinámico afirma que la explotación de estos ingresos conduce a distorsiones permanentes de los mercados de productos de capital y laborales en cuanto a la naturaleza de la obtención de rentas. La combinación de ambos argumentos lleva al fenómeno del crecimiento ultrasesgado, caracterizado por una especialización casi exclusiva en bienes comerciables con ventaja competitiva extraordinaria y en bienes no comerciables.

Si los auges exportadores fueran permanentes y la economía careciera de distorsiones, esta especialización tendría escasa importancia para el crecimiento a largo plazo. Sin embargo, los auges exportadores son por naturaleza fenómenos transitorios (aunque puede haber varios auges exportadores sucesivos), y su explotación crea varias distorsiones, por ejemplo, en el mercado de capitales, donde la tasa de descuento privada contendrá un elemento de renta espuria. Como la obtención de rentas espurias no aumenta el valor agregado (producto), el crecimiento de la producción tenderá a descender con el tiempo, ya que se impide la formación de capital. Si suponemos imperfecciones en los mercados laborales y de tierras, el proceso de erosión del auge exportador se acelera, a medida que surge la búsqueda de salarios supracompetitivos, así como de beneficios espurios mediante la concentración de derechos de propiedad. $\mathrm{Si}$, además, agregamos al argumento la existencia de la competencia internacional, que hace que la economía exportadora sea un agente económico sin influencia en el precio en los mercados internacionales, resulta claro que los beneficios económicos se disipan y que los auges exportadores son por naturaleza fenómenos transitorios. No obstante, en teoria, bastaría con una tasa óptima de ahorro interno y acumulación de activos para mantener el potencial de crecimiento a largo plazo. Sin embargo, habida cuenta de las imperfecciones mencionadas, la acumulación de capital se limitará a la actividad en auge y no alcanzará a la tasa necesaria para un crecimiento óptimo de largo plazo. Por ende, el crecimiento ultrasesgado resultante es menor que el crecimiento potencial a largo plazo, y además de carácter "intermitente".

Por cierto que la intervención normativa puede alterar el efecto de los auges temporales. Pero el problema es si hay argumentos que demuestren que esas intervenciones van a aumentar el bienestar de las personas. Es teóricamente posible, si suponemos que las economías de escala, los efectos del aprendizaje tecnológico y externalidades similares son mayores en otros bienes transables que en los que están en auge, que una distorsión de los precios relativos inducida por políticas a favor de otros bienes transables pueda conducir a un crecimiento mayor a largo plazo e incrementar el bienestar. Sin embargo, depende del tipo de instrumentos que se utilicen y la manera de implementarlos.

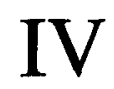

\section{Auge y caída de las exportaciones}

Se han elaborado series de largo plazo, en dólares constantes de 1980, para las exportaciones, el tipo de cambio efectivo real ${ }^{1}$, y el PIB (Buitelaar y Hofman, 1993). ${ }^{2}$ En los subpárrafos siguientes analizaremos tres ciclos de auges y caídas. El primero es el del cacao con un auge a comienzos del siglo $\mathrm{XX}$ seguido de su colapso y la diversificación de las exportaciones durante este siglo. La gran depresión y los años de la segunda guerra mundial no pueden considerarse como parte de un determinado ciclo ecuatoriano de auge y caída, y se

\footnotetext{
1 El tipo de cambio efectivo real se calculó sólo con el tipo de cambio nominal y los índices de precios al consumidor de los Estados Unidos y Ecuador. Se necesitaría un enfoque más refinado para conciderar el impacto de los instrumentos de política indus-
}

tratan en este ciclo hasta el término de la depresión (1937), y en el siguiente a partir de ese año en adelante. Este segundo ciclo comenzó realmente con el auge del banano a comienzos de los años cincuenta y duró hasta comienzos del auge petrolero en la década de 1970. El tercer ciclo (petróleo y deuda) continúa hasta ahora. En cada uno de estos subperíodos analizaremos los resultados con respecto al producto en auge y a las exportaciones distintas de aquellas poseedoras de ventajas comparativas extraordinarias.

\footnotetext{
trial y comercial. (Véase, por ejemplo, la obra de Schydlowski, $\mathbf{S}$. Levy, R. Parot, M. Rodríguez, S. Hunt e I. Mezzera, en el Center for Latin American Development Studies, Universidad de Boston.)

2 Estas series pueden solicitarce a los autores.
} 


\section{El ciçlo del cacao}

A comienzos del siglo XX Ecuador experimentó un período de rápido crecimiento económico en que las exportaciones de cacao fueron el elemento dominante. El auge previo a la primera guerra mundial se estimuló con la apertura del Canal de Panamá en 1914. Ecuador era el principal exportador mundial de cacao y poseía el 20\% del mercado. El auge llegó a su apogeo histórico entre 1908 y 1914. Las exportaciones ascendieron a unos 77 millones de dólares (dólares constantes de 1980) en los años 1914 y 1916. En 1918 declinaron, pero volvieron a repuntar a unos 60 millones de dólares en 1919-1920. El movimiento del tipo de cambio efectivo real fue el previsto. La moneda nacional se apreció hasta 1914, y se depreció considerablemente después de 1918. Esto sugeriría la presencia de la "enfermedad holandesa" en la segunda década (gráfico 2). Las demás exportaciones, compuestas principalmente de café, tagua, caucho y madera cayeron sostenidamente desde casi 37 millones de dólares en 1912 a una baja récord inferior a 11 millones de dólares en 19211922. Se confirma así la hipótesis de la "enfermedad holandesa" al producirse un fuerte descenso de las demás exportaciones durante el auge del cacao. La política económica de esos años suele caracterizarse por un régimen de laissez faire. No obstante, incluso así, las autoridades reaccionaron frente a las circunstancias económicas. Una economía agrícola fundamentalmente autosuficiente se transformó en esos años en una economía agroexportadora, y la fuente principal de ingresos tributarios, proveniente otrora de los gravámenes impuestos a los terratenientes serranos, pasaron a ser los impuestos a las importaciones, y más tarde a las exportaciones de cacao. Esta evolución económica acarreó una ruptura política en 1895, cuando la llamada revolución liberal transfirió el poder desde los terratenientes serranos precapitalistas a los agroexportadores capitalistas incipientes, es decir, a la naciente clase financiera y comercial del litoral.

También hay síntomas típicos de la "enfermedad holandesa" como es el "fuerte" gasto público, sobre todo en infraestructura. El proyecto de obras públicas más importante realizado en esos años fue la construcción del ferrocarril entre Quito y Guayaquil, para lo cual el gobierno obtuvo un préstamo en el extranjero. El ferrocarril se inauguró en 1908 y aumentó significativamente los contactos entre ambas ciudades principales. Esto se llevó a cabo durante el segundo gobierno del general Eloy Alfaro, período en que se realizaron también grandes obras de saneamiento y de alumbrado público en Quito y Guayaquil (mediante empresas extranjeras), así como cambios institucionales importantes (ley de educación, separación de la Iglesia y el Estado, etc.) (CEPAL, 1953).

En los años postreros de este ciclo (1926-1930) la estructura de las exportaciones se diversificó con la inclusión del café (fenómeno más bien espontáneo, producto de los precios favorables) y el arroz, lo que redujo la contribución de las exportaciones de cacao a menos de $50 \%$ de las exportaciones totales. Las exportaciones distintas del cacao subieron en los años veinte, luego de la depreciación de la moneda con un desfase cronológico de varios años. La totalidad de las exportaciones distintas del cacao se encumbraron de 18 millones de dólares en 1922 a 49 millones de dólares en 1928 , lo que redujo a menos de un tercio la participación de las exportaciones de cacao en el total. Por lo tanto, cabría concluir claramente que el colapso de estas últimas impulsó las reformas normativas, las que junto con una depreciación monetaria y los esfuerzos del sector privado para aumentar otras exportaciones parecen haber tenido los efectos deseados.

La gran depresión de comienzos de la década de 1930 puso término repentinamente a esta modesta recuperación, con lo que los ingresos totales de exportación bajaron a una cifra sin precedentes inferior a 30 millones de dólares en 1933. Nuevamente, las devaluaciones, los controles cambiarios y las alzas arancelarias fueron necesarias para ajustarse a un nivel extraordinariamente reducido de la capacidad importadora. Aun así, se agotaron las reservas de oro y divisas, lo que obligó a mantener un tipo de cambio real muy elevado hasta 1940.

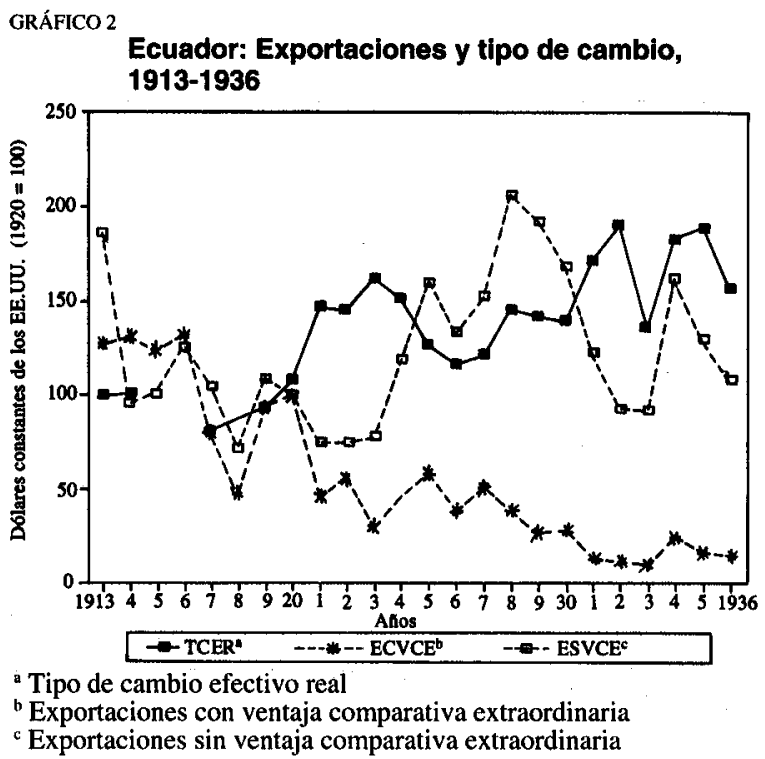




\section{El ciclo del banano (con un preludio que abar- ca los años de la segunda guerra mundial)}

Todas las exportaciones se recuperaron a partir de 1937. Hasta 1948 las exportaciones eran bastante diversificadas, como lo ilustra el notable repunte de las exportaciones de sombreros de jipijapa, el principal producto de exportación en 1945, que no obstante representaba poco más de $25 \%$ del total (es decir, 26 de los 103 millones de dólares constantes de 1958). El grueso de las exportaciones en esos años de la segunda guerra mundial consistía en arroz y café, este último considerado habitualmente como el cuarto producto de exportación del Ecuador. Sin embargo, no hay motivos para incluir un auge cafetero separado con posibles efectos de "enfermedad holandesa", ya que las exportaciones de café jamás fueron la fuente principal de ingreso de divisas $y$, por lo tanto, no puede suponerse que hayan modificado notoriamente la estructura interna de precios.

Las restricciones a las importaciones debido a la falta de oferta brindaron la oportunidad para una sustitución de importaciones "espontánea", pese a la fuerte apreciación de la moneda. Durante los años treinta se establecieron industrias importantes como la refinería de petróleo y una fábrica de cemento, así como otras industrias fundadas básicamente por inversionistas extranjeros. Un ejemplo típico de este fenómeno es la industria farmacéutica creada por un inmigrante italiano en 1940. Se dice que esta industria creció hasta emplear a no menos de 700 personas en los años cuarenta, y que exportaba a la mayoría de los países sudamericanos.

Exactamente cuán "espontánea" fue esta sustitución de importaciones es una cuestión debatible, puesto que los aranceles a las importaciones eran bastante elevados: la CEPAL reporta aranceles de entre 25 y $30 \%$ para las materias primas, de entre 30 y $90 \%$ para los insumos intermedios, y de hasta $265 \%$ para los productos terminados. El término "espontáneo" se refiere no tanto a la falta de una política comercial como a la ausencia de fundamento en términos de la teoría económica, fundamento que fue formulado por la CEPAL alrededor de 1950. En todo caso, los años de la guerra estimularon el crecimiento industrial, pues el índice de producción industrial subió de 50 en 1939 a 100 en 1948. No obstante, la recuperación de los años de la guerra tiene que considerarse dentro de la perspectiva del país extremadamente pobre que era todavía Ecuador.

Otro período de beneficios imprevistos para la economía ecuatoriana sobrevino a comienzos de los años cincuenta, con el auge del banano. La causa principal del repunte de las exportaciones de este producto no obedeció a un alza notoria de precios, sino a que las plantaciones de Centroamérica, hasta entonces las productoras principales, sufrieron una plaga (la enfermedad de Panamá) que destruyó gran parte de sus cosechas. Las exportaciones ecuatorianas de banano subieron de 10 millones de dólares en 1948 a 113 millones de dólares en 1955.

Nunca hubo en este ciclo un colapso de proporciones como ocurrió con los otros dos auges importantes. Las exportaciones cayeron efectivamente a 96 millones de dólares en 1958, pero se recuperaron gradualmente a 184 millones de dólares en 1964. A mediados de la década de 1960 se produjo un cambio estructural en la posición del mercado ecuatoriano, cuando se introdujo en Centroamérica una nueva variedad resistente a las enfermedades. Los plantadores ecuatorianos reaccionaron de inmediato cambiando las variedades, pero el país perdió su posición de liderazgo en los mercados mundiales frente a los países centroamericanos. La agitación política en esa región desde fines de los años setenta en adelante restauró la posición del mercado ecuatoriano, y los precios favorables en los mercados mundiales hacia fines de la década de 1980 permitieron un alza récord de los ingresos de exportación bananeros de $433 \mathrm{mi}$ llones de dólares (a precios constantes de 1980) en 1990, auge que llegó a su término en 1992.

$\mathrm{Si}$ definimos las exportaciones de banano y cacao como aquellas basadas en una ventaja comparativa extraordinaria, y analizamos el desempeño de todas las demás exportaciones, advertimos un período inestable y más bien flojo en que el valor total de estas últimas fluctúa entre 120 millones de dólares $(1952,1957)$ y 87 millones de dólares $(1959,1961)$. Las exportaciones de café representan en esos años el grueso de las demás exportaciones.

El efecto de "enfermedad holandesa" del auge bananero puede expresarse, entonces, por el descenso del promedio sexenal de todas las demás exportaciones: de poco más de 115 millones de dólares en el período 1952-1957 a poco más de 100 millones de dólares en el período 1958-1963. Si es que éste es un efecto de esa "enfermedad", es decididamente más benigno que la reacción consecutiva a la caída del cacao. En 1965 se registró un aumento considerable de las demás exportaciones, cercano a los 150 millones de dólares, que se mantuvo hasta 1971.

A partir de 1955 el crecimiento se debilitó, las inversiones apenas aumentaron y la construcción se estancó. Se registraba un ambiente de crisis nacional 
en 1959 (revueltas), la inflación se aceleró y hubo que devaluar en 1961. No obstante, es difícil hablar de un colapso de las exportaciones bananeras ya que en 1971 éstas sobrepasaron los récords históricos. Fue el período de la creación de instituciones necesarias para llevar a la práctica la estrategia de sustitución de importaciones que gozaba entonces de amplia aceptación. En 1954 se creó la Junta Nacional de Planificación y Coordinación Económica y en 1957 se promulgó la primera Ley de Fomento Industrial. Ésta otorgaba la exoneración total de impuestos a las importaciones de bienes de capital y reducciones considerables de otros impuestos a las importaciones; también autorizaba exenciones tributarias sobre las utilidades reinvertidas. En 1963 se creó la Corporación Financiera Nacional y en 1962 el Centro de Desarrollo Industrial, que presta asistencia técnica.

Hacia 1970 se había completado el marco legal e institucional de la estrategia de industrialización mediante sustitución de importaciones: los cambios en la estructura del arancel de importaciones de 1971 consolidaban tasas de protección efectivas elevadas y dispersas, principalmente para los bienes de consumo; en 1970 se fijó legalmente la tasa de interés en $12 \%$ lo que significaba tasas reales negativas; se había consolidado un complejo sistema de beneficios tributarios y exoneraciones arancelarias para las industrias, así como prohibiciones y licencias de importación mediante revisiones periódicas de la Ley de Fomento Industrial. La escala limitada del mercado interno era un problema conocido y la solución que se adoptó consistió en suscribir proyectos ambiciosos de cooperación regional en el contexto del Pacto Andino. El único elemento ausente de esta estrategia eran los recursos para invertir e importar.

Entre 1955 y 1972 las industrias para el mercado interno (en un sentido amplio) pasaron a ser el elemento más dinámico de la economía. Estas comprenden los servicios públicos no comerciables (agua, electricidad y saneamiento), que crecieron a una tasa de $15 \%$ anual en los años cincuenta y el sector servicios, que creció con más rapidez que el resto de la economía. Pero también la industria manufacturera fabril creció a un $10 \%$ o más en esos años, espoleada por los incentivos gubernamentales y el crédito barato. Sin embargo, el crecimiento manufacturero global fue menor (5\% anual) debido al estancamiento de la pequeña empresa y la artesanía.

Dentro del sector manufacturero, los sectores tradicionales alimentario y textil siguieron siendo los que más contribuyeron al crecimiento, junto con el sector de productos químicos, que recibió un gran impulso de la producción bananera, que utiliza gran cantidad de plaguicidas y productos plásticos como dispositivos para proteger la fruta. Pero la mayoría de las demás industrias, incluida la elaboración de metales y otras industrias avanzadas también tienen su (modesto) origen en este período. La producción azucarera constituye un caso especial, pues se triplicó con creces después que se otorgó una cuota a Ecuador en el mercado estadounidense en 1960.

\section{El ciclo del petróleo y de la deuda}

\section{a) Desempeño de las exportaciones y política económica}

Las inversiones en prospección petrolera llevaron al descubrimiento del oro negro en la región amazónica en 1967 y a un aumento importante de la capacidad de producción a comienzos de los años setenta. El alza considerable del precio internacional en 1973 suministró al país una afluencia de divisas que sirvió para superar dos de los problemas estructurales básicos de los años anteriores: el bajo nivel de ahorro y demanda internos, y la poca capacidad de importar. Los ingresos petroleros se elevaron desde cifras prácticamente nulas en 1971 hasta llegar a 1160 millones de dólares en 1974, lo que representó casi $2 / 3$ del total de los ingresos de exportación de ese año. En 1980 volvieron a subir y en 1985 llegaron al récord histórico de 1400 millones de dólares (en dólares constantes de 1980). La inversión pública creció rápidamente en la década de 1970, canalizada, por ejemplo, mediante el programa del Fondo NacioGRÁFICO 3

Ecuador: Exportaciones y tipo de cambio, 1972-1990

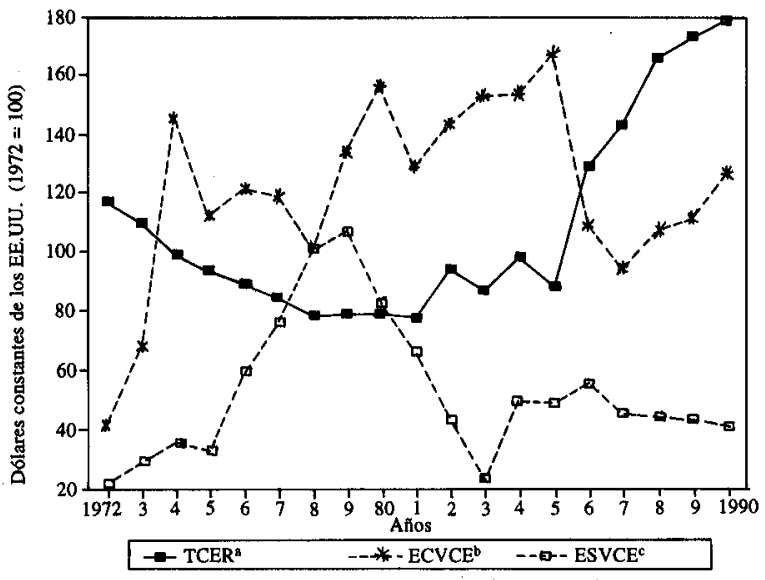

"Tipo de cambio efectivo real

' Exportaciones con ventaja comparativa extraordinaria

- Exportaciones sin ventaja comparativa extraordinaria 
nal de Desarrollo (FONADE), que limitó eficazmente el peligro de sobreexpandir el gasto de consumo del gobierno. La inflación se mantuvo controlada manteniendo deliberadamente bajos los sueldos de los empleados públicos. La mayoría de las políticas sectoriales estaban orientadas al consumo, en el sentido de que el objetivo básico era suministrar bienes salariales a bajos precios.

Las exportaciones de productos sin ventajas comparativas extraordinarias (VCE) (es decir, todas menos el cacao, el banano y el petróleo) casi se septuplicaron entre 1969 y 1979 . Alcanzaron su valor récord de 950 millones de dólares a fines del primer período de auge petrolero. Este resultado es, por cierto, un fenómeno que no concuerda con el argumento de la "enfermedad holandesa", y exige una explicación tanto en términos de política económica como de efectos de eslabonamiento. Dos tercios de estas exportaciones sin VCE provienen de dos fuentes vinculadas con las exportaciones con VCE: los derivados del petróleo y los derivados del cacao. Las exportaciones de chocolate no emanaron exclusivamente de los efectos de eslabonamiento, sino que fueron estimuladas por orden del gobierno militar de esa época, que obligó a los productores de cacao a incrementar la capacidad de producción de chocolate. Un buen número de otros productos también registraron alzas considerables.

El auge de la demanda interna y la posibilidad de importar bienes de capital abonaron el terreno para un rápido aumento de la producción manufacturera, facilitada además por los beneficios tributarios otorgados por la Ley de Fomento Industrial, que favoreció a la mitad de todas las empresas (un total de 800 empresas se acogieron a los beneficios de esa ley).

Otros incentivos fueron los precios baratísimos de la energía y el gas. En forma esquemática podemos decir que los ingresos del petróleo se canalizan hacia la industria manufacturera mediante una serie de mecanismos como:

- energía y gas baratos;

- tasas de interés subvencionadas, negativas en términos reales;

- exenciones tributarias para las importaciones de bienes de capital;

- beneficios tributarios para las nuevas industrias;

- represión salarial, viabilizada mediante la política de control de precios de los bienes de consumo básicos;

- lenta apreciación de la moneda nacional, lo que abarataba las importaciones de bienes de capital;
- fuerte protección de la industria nacional mediante aranceles elevados -básicamente sobre los productos terminados-, licencias de importación, requisitos de depósito previo, etc.

Ello llevó en los años setenta a un rápido aumento de la producción manufacturera (casi $10 \%$ anual), merced al establecimiento de una serie de pequeñas empresas en un gran número de actividades. Supuestamente, el sector manufacturero resultante estaba sobredimensionado, pues utilizaba en forma intensiva la energía y el capital pero no la mano de obra, ya que la rigidez de las leyes laborales disuadía a los empresarios de otorgar contratos de trabajo de largo plazo. Asimismo, el sector industrial provocaba grandes déficit de balance de pagos y los eslabonamientos tanto dentro del sector como con el resto de la economía tenían escaso desarrollo. La menos beneficiada de todos los sectores productivos con estos mecanismos que canalizaban los ingresos del petróleo al resto de la economía era la agricultura, ya que su crecimiento era el más bajo (Vos, 1984).

Aunque el gasto público aumentó, los ingresos fiscales disminuyeron ya que dependían excesivamente de los ingresos petroleros. Las exportaciones de petróleo permanecieron más o menos estables durante el período 1975-1982. Esto, sumado a un tipo de cambio fijo y un sesgo antiexportador importante, provocó déficit fiscales y problemas de balance de pagos en los últimos años de la década de 1970. Los ajustes podían postergarse ya que los bancos internacionales estaban más que dispuestos a aumentar los empréstitos y la deuda internacional se disparó. Los ajustes tanto tiempo postergados se volvieron a la larga inevitables cuando subieron las tasas internacionales de interés y se suspendieron las transferencias de capital después que México entró en moratoria del servicio de la deuda en septiembre de 1982 (Acosta, 1990).

El efecto previsto de "enfermedad holandesa" de las exportaciones declinantes de otros productos puede observarse en el período siguiente, entre 1979 y 1983. A estas alturas se había desarrollado un nuevo producto con ventajas comparativas extraordinarias: el camarón. El valor de las exportaciones de este producto subió de 30 a 300 millones de dólares constantes entre 1978 y 1990 . De modo que también tenemos que restar del total las exportaciones de camarón. Todas las demás exportaciones se desplomaron a 207 millones de dólares en 1983, recuperándose a 490 millones de dólares en 1986, para volver a caer sostenidamente con posterioridad.

A comienzos de los años ochenta el auge petro- 
lero, el rápido crecimiento económico y las grandes mejoras sociales llegaron a su término. En 1980 cayó la producción petrolera y en 1981 el crecimiento económico per cápita fue muy reducido. El auge de los años setenta había dejado al Ecuador muy mal preparado para el decenio siguiente. La competitividad de su sector agrícola se había debilitado y el sector manufacturero subvencionado había aumentado demasiado sin volverse competitivo en el plano internacional. El sector público había crecido con rapidez, de $23 \%$ del PIB en 1973 a más de $30 \%$ en 1982. Sin embargo, esta expansión del sector público se financiaba casi exclusivamente con los ingresos del petróleo y la deuda externa.

La crisis de la deuda estalló en 1982 y acarreó una reversión de las transferencias de capital con los problemas consiguientes de balance de pagos. Sin embargo, las exportaciones de petróleo no declinaron (tras la caída de 1980-1981) hasta que su precio sufrió un colapso en 1986 y un terremoto destruyó el oleoducto en 1987. Las exportaciones declinaron: cacao en 1983, banano en 1984, camarones en 1985 y petróleo en 1987. En general, observamos períodos de exportaciones declinantes entre 1980 y 1983, una leve recuperación en 1984-1985, un colapso en 1986-1987 y una recuperación muy modesta con posterioridad. La crisis de la deuda puso término a las posibilidades de crecer con endeudamiento y el gobierno del Presidente Hurtado se vio forzado, por primera vez desde 1970, a devaluar el sucre e introducir un paquete de políticas de estabilización. El paquete incluyó la reducción del déficit fiscal, que pasó del $7 \%$ del PIB en 1982 a un pequeño superávit en 1984. Se introdujeron restricciones a las importaciones para mejorar la balanza comercial. Sin embargo, la reducción del déficit se financió en buena parte mediante la creación de dinero lo que provocó un aumento de la inflación y una caída del PIB per cápita en 1982 y 1983.

Fue el gobierno del Presidente Febres Cordero, el que inició en 1984 un gran programa de estabilización tendiente también a modernizar la economía mediante una serie de medidas contenidas en un programa neoliberal (o neoconservador). Asimismo, se pretendía reducir la intervención directa del Estado en la economía y la maraña de reglamentaciones. Esto incluía también eliminar los controles de precios y los subsidios (por ejemplo, a la energía) y liberalizar el comercio y el tipo de cambio. Significaba asimismo pasar de la sustitución de importaciones al fomento de las exportaciones manufactureras. Mediante este programa se fomentó la inversión extranjera di- recta y el servicio integral de la deuda vino a mejorar la imagen del Ecuador. Este programa tenía similitudes con los programas iniciados antes en Chile, Argentina y Uruguay, pero con grandes diferencias en el contexto económico y político (Ramos, 1986).

Los resultados iniciales del programa fueron relativamente positivos ya que el PIB creció más de $4 \%$ en 1984 y 1985, principalmente a expensas de la recuperación del sector agrícola tras las inundaciones de 1983. Sin embargo, la intranquilidad social crecía en el país, pues los costos sociales del programa de una política monetaria y fiscal restrictiva fundada en la eliminación del control de precios, la devaluación, y la caída del empleo, de los subsidios gubernamentales y de los salarios reales, afectaban a gran parte de la población. La pérdida de respaldo político, agravada por la caída de los precios del petróleo en 1986 , relajó la austeridad fiscal y dio inicio a un programa de obras públicas, con los consiguientes déficit presupuestarios y aumentos de la tasa inflacionaria en 1986 y 1987. El terremoto de 1987 que destruyó el oleoducto entre la región amazónica y el litoral, y una nueva caída del precio del petróleo en 1988 provocaron los desastrosos resultados de la economía a fines del gobierno de Febres Cordero.

Todavía no se percibe claramente el repunte previsto de las demás exportaciones tras el colapso del petróleo en 1986, pero tal vez debamos tener presente que históricamente esta reacción de las exportaciones sin VCE consecutivas a la vigencia de un tipo de cambio efectivo real elevado tardaba varios años. Las exportaciones totales menos las de petróleo, cacao, camarones y banano declinaron de 490 millones de dólares (a precios constantes de 1980) a 322 millones de dólares en 1990. No obstante, en esta tendencia influyeron fuertemente el café, los derivados del petróleo y el chocolate. Algunas exportaciones menores parecen estar recobrándose, sin llegar a una escala que incida en el cuadro general.

El gobierno de Borja asumió en 1988 y ha conseguido recuperar las reservas internacionales, pero no ha avanzado gran cosa en la modernización de la economía ecuatoriana. $\mathrm{El}$ desempeño ha sido más bien pobre, con un crecimiento per cápita nulo durante todo el período 1988-1992. Sin embargo, el crecimiento del PIB se ha acelerado un poco a fines de este gobierno. La inflación se ha mantenido persistentemente elevada, en torno a $50 \%$, durante todo el periodo. Una de las causas de esta inflación persistente ha sido la incapacidad del gobierno para combinar en forma eficiente la política monetaria y la fiscal. Mientras la política monetaria era más bien restrictiva, esto no ocurría con la físcal. 


\section{Política económica}

El deficiente desempeño de las exportaciones manufactureras y la ineficiencia productiva caracterizan al sector industrial ecuatoriano ${ }^{3}$, situación que han acentuado las políticas económicas. En esta sección se examinan en especial la política comercial, la política cambiaria y la inversión extranjera directa.

\section{Política comercial}

Ecuador posee una larga tradición en la aplicación de reglamentaciones a las exportaciones que intensificaron más el sesgo contra aquéllas, como ser los permisos de exportación, la prohibición de exportar y la regulación de los ingresos en divisas. La protección interna, cuyo efecto es bajar los precios relativos de los bienes exportables en comparación con los sustitutos importados y los bienes no comerciables, consistía en un sistema muy complicado que comprendía cuatro listas arancelarias distintas, cada una regida por tipos de cambio diferentes hasta 1985 , un sistema de exoneraciones tributarias que eran en gran medida peculiares de cada empresa, solicitud de autorización previa para efectuar determinadas importaciones, prohibición de importar y autorizaciones cambiarias. Durante los años ochenta la protección mediante aranceles y sobretasas aumentó y disminuyó en varias ocasiones. En 1983 se agregaron nuevas sobretasas que aumentaron la tasa de protección. En 1986 se introdujo una nueva estructura arancelaria que rebajó las tasas y redujo su dispersión, pero en 1989 se introdujeron nuevos gravámenes a las importaciones. A fines de 1992 Ecuador abandonó sus objeciones previas contra el área de libre comercio del Pacto Andino. Las importaciones de Colombia y Bolivia ingresan libre de derechos desde septiembre de 1992 y las de Venezuela desde febrero de 1993. En noviembre de 1992 se volvieron a reducir las tasas arancelarias al adoptar una nomenclatura arancelaria de 5 a $20 \%$ para las importaciones de fuera de los países miembros del Pacto Andino. También se ha progresado en la simplificación de los procedimientos de importación y exportación.

\footnotetext{
3 Para una descripción más general de la política económica y el proceso político, véase Hurtado, 1988, De Janvry, Sadoulet y Fa-
} reix, 1991, y Thoumi, 1990.

\section{El manejo del tipo de cambio}

Hasta marzo de 1983 el país tenía un sistema de tipo de cambio fijo que era relativamente estable. En el período 1950-1983 el tipo de cambio sólo varió en cuatro oportunidades, y pasó de 15 sucres por dólar en 1950 a 33 sucres por dólar en 1983. Hasta mediados de los años ochenta las políticas cambiarias discriminaban en contra de los bienes comerciables. El instrumento principal para manejar el tipo de cambio ha sido la intervención directa en la oferta de divisas, estimulada por las exportaciones de petróleo y el endeudamiento externo. Estas políticas fomentaron la producción intensiva en capital y, por ende, las importaciones de bienes de capital. En 1983, tras una macrodevaluación, se introdujo un sistema de paridad móvil que duró casi dos años tras lo cual el gobierno implantó un sistema cambiario dual. En 1986 se estableció un sistema de tipo de cambio libre, reservándose el oficial sólo para las importaciones gubernamentales y las exportaciones de petróleo. La inestabilidad macroeconómica provocó el colapso del mercado libre en 1988. Tras un breve experimento con un tipo de cambio fijo se volvió a establecer un sistema de paridad móvil que rigió hasta septiembre de 1992. Desde entonces el gobierno ha avanzado hacia un sistema de cambio libre, con intervención del Banco Central para estabilizar la tasa (flotación manipulada).

\section{La inversión extranjera directa}

En los últimos años se ha asistido a una liberalización del régimen de inversión extranjera. En 1991 las nuevas reglamentaciones disponían un trato igual para las empresas nacionales y extranjeras en términos de impuestos, aranceles y demás incentivos fiscales, eliminaban los límites a la repatriación de utilidades netas (derogando la norma que prescribía un tope equivalente a $40 \%$ del capital base de la empresa), lo que facilitó la inversión extranjera en sectores considerados hasta entonces estratégicos, tales como los servicios de utilidad pública, los medios de comunicación de masas, la publicidad y el transporte interno. A comienzos de 1993 el gobierno que recién asumía la liberalizó aún más eliminando las 
restricciones restantes sobre su participación en la banca comercial y haciendo extensivos a las empresas extranjeras los mecanismos promocionales disponibles para las empresas ecuatorianas. Esta nueva situación permite que los inversionistas y empresas extranjeros pasen a ser inversionistas locales sin registrarse o cumplir requisitos específicos y elimina la autorización previa para transferir acciones de ca- pital. También se ha relajado la reglamentación sobre transferencia de tecnología.

A mediados de 1991 se aprobó un nuevo código de inversiones que brinda igual trato a las empresas nacionales y extranjeras en cuanto a incentivos fiscales, elimina restricciones a la repatriación de utilidades y permite la inversión extranjera en varios sectores que antes le estaban vedados.

\section{VI}

\section{Comportamiento empresarial}

Las industrias que atienden la demanda interna ecuatoriana suelen clasificarse en cuatro subgrupos, que poseen características diferentes en cuanto al tipo de empresas involucradas (propiedad, tamaño), y al tipo de intervención gubernamental a que están sujetas. Por lo tanto, podemos suponer también que son diferentes en cuanto a las estrategias que aplican en respuesta a los cambios del entorno normativo. Estos subgrupos serían los siguientes:

- Industrias orientadas a las necesidades básicas, con controles de precios y estructuras de mercado oligopolísticas.

- Industrias de bienes de consumo tradicionales, algunas de las cuales poseen un neto trasfondo autóctono que suelen operar en mercados más bien competitivos, pese a la frecuente elevada protección arancelaria.

- Industrias de bienes de consumo durables, con cuasimonopolios privados en mercados muy reglamentados.

- Industrias de insumos industriales y agrícolas, a menudo vinculados con empresas que dominan las exportaciones de productos tradicionales.

Las distorsiones inducidas por las políticas son mayores en el primer y el tercer subgrupos de industrias y, por ende, los cambios de conducta empresarial frente a las variaciones de aquéllas tienden a ser mayores en estos dos subgrupos, los que se examinan a continuación.

\section{Industrias que satisfacen necesidades esenciales ${ }^{4}$}

En este subgrupo cabe clasificar las industrias azucarera, arrocera, de aceites y grasas, farmacéutica y del

4 La descripción de estas industrias se basa en parte en Spurrier Baquerizo (ed.), varios números. cemento. Las políticas respecto a este tipo de industrias obedecían generalmente al objetivo esencial de mantener bajos los precios al consumidor, a fin de mitigar la intranquilidad social derivada de los bajos salarios. Esto plantea el problema de cómo garantizar una tasa de utilidad aceptable, lo que suele requerir el establecimiento de controles de precios en toda la cadena productiva. Hay que prohibir las exportaciones, porque de otro modo los consumidores extranjeros se beneficiarían de los precios al consumidor subvencionados. Como la tasa de utilidad depende de decisiones gubernamentales en cuanto a niveles de precios, los incentivos para invertir en expandir la capacidad productiva, o en esfuerzos de modernización para mejorar la eficiencia son muy escasos. En definitiva, la producción no bastará para satisfacer el consumo interno (subsidiado), y habrá que importar. Las importaciones tendrán que subsidiarse, lo que es otra forma de encauzar los beneficios hacia los productores. Algunos ejemplos podrían aclarar estos puntos.

En la industria azucarera, la caña se elabora en tres ingenios principales, uno de los cuales es de propiedad estatal (de la CFN). La cuota establecida para el mercado estadounidense hace que las exportaciones azucareras sean una operación muy rentable. La empresa estatal de venta al detalle, denominada Empresa Nacional de Almacenamiento y Comercialización de Productos (ENAC), distribuye la cuota entre los ingenios, pero a cambio, los obliga a venderle toda el azúcar para el consumo interno. Los controles de precios operan en toda la cadena: desde el precio entre los productores de caña y los ingenios, hasta el precio de venta al público del producto. Como la producción azucarera no basta para satisfacer el consumo interno, se otorgan permisos de importación para complementar la oferta 
en el mercado interno y reexportar a los Estados Unidos. El efecto presunto sobre la conducta empresarial es que no hay incentivo para invertir en una mayor capacidad productiva, ni para mejorar la productividad en las plantaciones o en las fábricas.

Una situación similar se observa en el sector del arroz, que sigue siendo un producto importante ya que una cantidad significativa de pequeños agricultores se dedica a producirlo. Se emplean los controles de precios, pero no pueden ponerse en vigor con tanta facilidad como en el caso del azúcar. Los molinos de granos están obligados a vender a la ENAC. Cuando se elevan los precios, la producción aumenta fácilmente y hay que exportarla, lo que produce déficit para la ENAC, ya que los precios para el productor nacional son inferiores (supuestamente muy subvencionados) a los precios de los mercados mundiales. Esta saturación del mercado lleva al gobierno a bajar los precios, lo que disminuye el cultivo del arroz y obliga a importarlo. La ENAC sigue sufriendo pérdidas, pues hay que subsidiar los precios al consumidor. La lucha política interminable por los precios del arroz es un asunto explosivo, que ha ocasionado la destitución de ministros de agricultura.

De las cuatro plantas que dominan la producción de cemento, una es de propiedad estatal. Hasta hace muy poco se utilizó el control de precios, mediante la fijación de la tasa de utilidades de la industria. La capacidad de producción se utilizaba al máximo, pero la escasez de cemento en el mercado era la regla. Los precios en el mercado negro eran prohibitivos, e incluso se decía que se contrabandeaba cemento a Colombia. Sin embargo, los controles de precios impedían que se realizaran inversiones para expandir la capacidad de producción. El gobierno de Borja subió los precios del cemento y abolió el control de las importaciones con lo que desapareció el mercado negro y cayó la demanda. La Corporación Andina de Fomento propuso un importante proyecto de inversión para aumentar la capacidad productiva.

La industria farmacéutica tiene también una participación importante en la canasta de consumo de la población. Resulta quizás sorprendente que ya desde los años cuarenta el sector haya tenido un buen desempeño y exportado con frecuencia, pese a servirse de principios activos importados, que representan alrededor de la mitad de los costos de producción. La mayoría de las empresas transnacionales del rubro se establecieron en Ecuador, y en 1987 había más de 100 laboratorios registrados, de los cuales los 26 más grandes representaban el $80 \%$ de la producción, aun- que sólo dos de ellos son de capital ecuatoriano. Las rígidas políticas de precios estaban destinadas a mantener bajos los precios al consumidor. Esto fue posible durante la década de 1970 porque las importaciones eran baratas expresadas en sucres. Las devaluaciones a partir de 1982 disminuyeron los niveles de utilidades, y las empresas declararon pérdidas. El gobierno decidió otorgar subsidios basados en el volumen de importaciones. Los laboratorios siempre protestaron contra estos subsidios, pues sostenían que la mejor solución era la abolición de los controles de precios. Los subsidios entrañaron un sacrificio fiscal cercano a 50 millones de dólares en 1990. Naturalmente que hubo que prohibir las exportaciones y se produjo un contrabando masivo (hasta $30 \%$ de la producción total). Por último, en septiembre de 1991, el gobierno anunció la eliminación del subsidio y su reemplazo por un subsidio directo a los grupos de bajos ingresos. Sin embargo, para descontento de los laboratorios no se eliminaron los controles de precios. No obstante, los empresarios hacen hincapié en la competitividad del sector en el mercado andino, y confían en que las empresas transnacionales podrían preferir a Ecuador como base de producción para el mercado regional. Esto dependerá de la eliminación de la prohibición de exportar y la incidencia de otras políticas comerciales y de inversión extranjera.

Estos ejemplos muestran claramente los efectos colaterales negativos de los controles de precios para mantener bajos los precios al consumidor.

\section{Industrias de bienes de consumo durables}

Tal vez el ejemplo más conocido de las políticas industriales ecuatorianas sea el establecimiento de industrias productoras de bienes de consumo durables. Se perseguía gàrantizar una elevada tasa de rentabilidad para las nuevas empresas subvencionando las inversiones y asegurando un mercado. Los subsidios a la inversión consistieron en créditos con tasas de interés negativas y exenciones arancelarias para las importaciones de bienes de capital. Los mercados se aseguraron mediante una protección arancelaria elevada y la suscripción de acuerdos regionales dentro del plan de integración del Pacto Andino. En estas condiciones la relación precio-calidad realmente no interesaba para obtener utilidades. La mayoría de las industrias no desarrollaron una capacidad competitiva genuina en los mercados abiertos, y prácticamente desaparecieron después del cambio de las políticas económicas. Una excepción es la industria automovi- 
lística, en que los cambios de políticas tardaron en implementarse, por lo que su competitividad en los mercados abiertos está aún por verse.

La historia de la industria automovilística ecuatoriana está estrechamente vinculada con los esfuerzos comunes de industrialización de los países del Pacto Andino. Antes del Pacto Andino había una sola empresa armadora, vinculada con la General Motors, y unos pocos proveedores de partes y piezas. La política automotriz de los países del Pacto Andino no tuvo todos los efectos deseados, pero otras dos empresas ingresaron al mercado. En 1983 se implantó una política más proteccionista, y la Volkswagen se instaló en Ecuador. El instrumento principal fue la autorización para importar equipos totalmente desmontables (ETD), y la prohibición absoluta de efectuar otras importaciones. Esta prohibición absoluta se relajó por un tiempo entre 1985 y 1987 , pero se mantuvieron aranceles de importación elevadísimos. CORDINAUTO, el organismo coordinador, distribuyó las autorizaciones de importación de ETD entre las empresas. En el segundo lustro de los años ochenta estas autorizaciones se emplearon para llevar a la práctica el programa conocido como el automóvil económico. Conforme a esta normativa, $40 \%$ de todas las importaciones de ETD debían ser de automóviles baratos. El programa hizo que florecieran las operaciones de montaje local. En 1991 se suspendió el programa, y las importaciones de ETD pasaron a hacerse sin restricciones. Se eliminó el plan automotriz del Pacto Andino, y se estimuló la libre importación desde los países miembros. La industria automotriz ecuatoriana no parece temer la competencia de Colombia, Perú o Venezuela. La mayoría de las empresas son propiedad de una casa matriz que también posee filiales en los demás países. De modo que se está dando una estrategia de especialización entre las filiales, en que las empresas ecuatorianas exportan automóviles baratos a Perú y Colombia, e importan a su vez los modelos más lujosos desde esos países, especialmente desde Venezuela. No obstante, las perspectivas de la industria en un escenario de liberalización hacia terceros países resultan menos claras, las que podrían materializarse después de 1993.
Entre las demás industrias que se han beneficiado hasta cierto punto del impulso de las políticas de industrialización del Pacto Andino figura la de refrigeradores, una rama que registró exportaciones a los países miembros hasta por 80 millones de dólares a fines de la década de 1970. El término de la estrategia de industrialización del Pacto Andino paralizó por completo este impulso exportador. La misma experiencia tuvieron las industrias de transformación de la madera. Las cuatro empresas del rubro colapsaron después del quiebre de la política común. De las 15 empresas que ingresaron a la industria metalmecánica conforme a las políticas del Pacto Andino, sólo quedan cuatro en producción. Estas últimas, que producen sistemas eléctricos, sembradoras, aspiradoras y sistemas hidráulicos, exportaron en conjunto productos por 8 millones de dólares en 1989. En el sector de productos químicos al menos dos empresas sobrevivieron al término de las políticas de industrialización del Pacto Andino, ambas pertenecientes a la industria farmacéutica. La experiencia con el plan de industrialización en el contexto de la integración andina no ha brindado al Ecuador una capacidad duradera importante en ninguna rama, salvo algunas excepciones concretas. La mayoría de las empresas simplemente no pudieron sobrevivir sin protección.

A fin de corroborar esta última aseveración, se ha calculado la participación del Ecuador en las importaciones de la OCDE para los años 1963, 1971, 1980 y 1990, a nivel de la clasificación de tres dígitos de la CUCI. Sólo se han tomado en cuenta los productos con una participación en el mercado de al menos $0.01 \%$ de las importaciones de la OCDE. El auge petrolero coincide con el período exportador más dinámico tanto de los productos con VCE como de los no tradicionales. Se confirma una caída de la competitividad en el período 1979-1983, que avala el argumento del mal holandés. Entre 1983 y 1989 se registra todavía una recuperación muy modesta de las posiciones competitivas, básicamente de las exportaciones con VCE distintas del petróleo.

\section{VII}

\section{Resumen y conclusiones}

Ecuador está en vías de implementar una nueva estrategia de desarrollo la que, como en muchos otros países latinoamericanos, comprende un cambio de rumbo hacia una estrategia más orientada hacia afuera. La transformación del régimen comercial y de industrialización debería tomar en consideración una de 
las características esenciales del crecimiento ecuatoriano, a saber, su inestabilidad emanada de la existencia de ventajas comparativas extraordinarias.

Durante el siglo XX Ecuador creció con bastante rapidez: el crecimiento global per cápita entre 1900 y 1989 fue de $2.2 \%$ comparado con $1.7 \%$ para el promedio de América Latina y 2.3\% para los países en desarrollo de Asia. Pese a que desde 1950 el crecimiento per cápita del Ecuador ha sido mucho más rápido que el promedio latinoamericano, los países asiáticos duplicaron con creces ese crecimiento.

En este artículo hemos analizado los diferentes auges y caídas que han ocurrido en Ecuador en el siglo $\mathrm{XX}$. El auge del cacao a comienzos de siglo seguido de su caída en los años veinte y la gran depresión de los años treinta; el auge bananero de los años cincuenta y su declinación en los sesenta y, por último, el auge petrolero durante los años setenta y la crisis de la deuda en la "década perdida" de los ochenta. Ecuador experimentó un problema definido de "enfermedad holandesa" durante el auge del cacao a comienzos de siglo. El crecimiento de los bienes no comerciables -como los indispensables servicios públicos-, la inflación y el deterioro de la competitividad de las demás exportaciones fueron las señales. Ya en 1921 era evidente que había que diversificar las exportaciones, por lo que se crearon varios instrumentos normativos para lograrlo: aranceles de importación, controles cambiarios, asignación de créditos y beneficios tributarios a otras industrias. Se lograron algunos resultados en el segundo lustro de los años veinte. Sin embargo, la gran depresión paralizó las exportaciones. La recuperación después de 1937, la sustitución espontánea de importaciones y la diversificación de las exportaciones fue un fenómeno anormal, producto de la desorganización existente en los países desarrollados. Las exportaciones bananeras de los años cincuenta, sin constituir un auge de la magnitud de los del cacao y el petróleo, permitieron el fortalecimiento del gobierno y de las instituciones financieras, y la aceleración de la inversión pública. Se creó un sistema institucional orientado a una estrategia de sustitución de importaciones. Un indicio de los problemas causados por la "enfermedad holandesa" puede advertirse en el magro desempeño de las demás exportaciones entre 1955 y 1965 . Pero las industrias manufactureras nacionales nacieron y crecieron a un ritmo considerable.

Los ingresos petroleros suministraron los recursos financieros que complementaron el sistema institucional para llevar a la práctica la estrategia sustitutiva. Esos ingresos se canalizaron hacia la industria manu- facturera mediante un sinnúmero de mecanismos directos e indirectos, suficientes para contrarrestar los efectos de la "enfermedad holandesa". Todas las exportaciones crecieron y se diversificaron hasta 1978. La afluencia de divisas mediante la acumulación de la deuda exacerbó los problemas causados por la "enfermedad holandesa", y los datos sobre las exportaciones indican claramente el debilitamiento de la competitividad en el período 1978-1982/1983. Esto fue seguido de una estrategia de ajuste gradual entre 1982 y 1984 , y después de este último año se ensayó un cambio en la estrategia de desarrollo. Se abolieron de hecho los créditos y beneficios fiscales. Dicho cambio se consolidó después de 1988 cuando se implantaron las reducciones arancelarias y las desreglamentaciones. Cabe esperar una acentuación de la estrategia liberalizadora en el futuro cercano. La estrategia deliberada de sustitución de importaciones duró aproximadamente 30 años, de 1955 a 1985, y modificó bastante los efectos de la "enfermedad holandesa", permitiendo la generación de cierta capacidad manufacturera y la diversificación de las exportaciones, sobre todo subvencionando a los productores con los ingresos petroleros. No creó un sector manufacturero competitivo que pudiera competir sin subsidios, salvo tal vez en el caso de determinadas empresas.

Pero es difícil que el retorno a una estrategia de desarrollo basada exclusivamente en los mecanismos del libre comercio produzca un crecimiento estable orientado a la exportación, ya que la economía ecuatoriana se caracteriza aún por la presencia de ventajas competitivas naturales extraordinarias, $\mathrm{y}$ abundan las distorsiones en los mercados internos. No es del todo inimaginable que el Ecuador experimente un segundo auge petrolero, tal como experimentó un segundo auge bananero entre 1987 y 1991. O tal vez que un nuevo producto venga a alterar notoriamente la composición de las exportaciones, tal como lo hizo sorpresivamente el camarón en los años ochenta. ¿Irá a ser la madera dura tropical el próximo producto que aporte ingresos considerables al Ecuador, transformando la selva húmeda tal como el cacao y el banano transformaron la zona costera?

Subsiste el interrogante de cómo optimizar estos beneficios imprevistos a fin de crear ventajas competitivas en otras áreas y diversificar y, por lo tanto, estabilizar, las exportaciones como objetivo final del crecimiento. El libre comercio sin distorsiones no lo va a conseguir a menos que se suponga una economía sin distorsiones. El régimen de libre comercio no logró un crecimiento sustentable en el pasado. La dis- 
tribución de ingresos a los empresarios mientras se mantienen bajos los salarios reales, como en el período sustitutivo de importaciones, tiene graves inconvenientes como lo ilustran la menor capacidad de respuesta y la mayor vulnerabilidad del aparato productivo, sin mencionar las deficiencias macroeconómicas de gasto público excesivo e inflación.

El régimen de libre comercio y la presencia de ventajas competitivas extraordinarias distorsionan las señales de precios y los mecanismos de mercado en la economía nacional, a través de una conducta orientada a la obtención de rentas. Debe seguirse una estrategia de intervención consciente a fin de estabilizar, pero no inmovilizar, la estructura de precios relativos en el tiempo. Esto puede llevar a medidas protectoras o estimuladoras de otros bienes comerciables durante un auge. Pero las medidas concretas tomadas en el período 1955 1985 estaban descaminadas, si las evaluamos con un criterio de crecimiento a largo plazo. En un período de auge exportador, en vez de subvencionar a los productores debería subsidiarse a los consumidores, especialmente de los estratos de menores ingresos, brindándoles apoyo directo traducido, por ejemplo, en becas para la educación y capacitación básicas. Sin embargo, para desacelerar el gasto y estimular el ahorro habría que contar con una tasa de interés real elevada, en vez de las tasas negativas vigentes durante la industrialización sustitutiva. Deberían privilegiarse los mecanismos del seguro social para captar el ahorro y proporcionar recursos de largo plazo al sistema financiero. Es más, el auge de la demanda interna sería un gran estímulo para las industrias locales, que no deberían estar protegidas (para siempre) de la competencia internacional, sino que habría que familiarizarlas con las normas y prácticas internacionales. Aparte del inconveniente de que la protección de la competencia internacional perturba el aprendizaje tecnológico, las importaciones son necesarias para contener las presiones inflacionarias y moderar el comportamiento oligopolístico.

En suma, el desarrollo ecuatoriano requerirá la intervención pública en las fuerzas del mercado para alcanzar un crecimiento óptimo a largo plazo. Pero esa intervención requerirá a su vez otros mecanismos, otras instituciones y una mejor implementación que el tipo de intervención empleado hasta ahora. Hasta cierto punto será una intervención para crear y mejorar el funcionamiento de las fuerzas del mercado en la economía nacional, en vez de suprimirlas. La tarea de modificar el régimen de política económica se inició con la crisis de la deuda, pero la configuración del nuevo modelo todavía no es muy definida. Probablemente habrá que esperar hasta bien entrado el próximo siglo para lograr la consolidación de un conjunto de instituciones y mecanismos razonablemente articulados e integrados.

(Traducido del inglés)

\section{Bibliografía}

Abril-Ojeda, Galo (1990): Auge exportador y desarrollo en Ecuador, Magnus Blomström y Patricio Meller (coords.), Trayectorias divergentes. Comparación de un siglo de desarrollo económico latinoamericano y escandinavo, Santiago de Chile, Corporación de Investigaciones Económicas para Latinoamérica (CIEPLAN)/HACHETTE.

Acosta, Alberto (1990): La deuda eterna, Quito, Editorial "El Duende". Benalcazar R., René (1989): Análisis del desarrollo económico del Ecuador, Quito, Banco Central del Ecuador (BCE).

Bianchi, Andrés y Takashi Nohara (1988): A Comparative Study on Economic Development between Asia and Latin America, Joint Research Programme (JRP) Series, $N^{\circ}$ 67, Tokio, Institute of Developing Economies.

Blomström, Magnus y Patricio Meller (coords.) (1990): Trayectorias divergentes. Comparación de un siglo de desarrollo económico latinoamericano y escandinavo, Santiago de Chile, CIEPLAN/HACHETTE.

Buitelaar, Rudolf y André A. Hofman (1993): Ecuador: Extraordinary comparative advantage, economic policy and economic growth. Trabajo presentado a CEPAL/CEDLA Conference on Industrialisation in Smaller Latin Americam Countries, Amsterdam, julio, mimeo.

CEPAL (Comisión Económica para América Latina y el Caribe) (1953): El desarrollo económico del Ecuador, México, D.F Publicación de las Naciones Unidas, $\mathrm{N}^{\circ}$ de venta 1953. II. G. 5.
(1990): Transformación productiva con equidad (LC/G. 1601-P), Santiago de Chile. Publicación de las Naciones Unidas, $\mathbf{N}^{\circ}$ de venta S.90.II.G.6.

(1992): Equidad y transformación productiva: Un enfoque integrado (LC/L. 668), Santiago de Chile.

De Janvry, Alain, Elisabeth Sadoulet y André Fargeix (1991): Politically feasible and equitable adjustment: Some alternatives for Ecuador, World Development, vol. 19, № 11, Nueva York, Pergamon Press PLC.

Drake, Paul (1984): La misión Kemmerer en el Ecuador: revolución y regionalismo, Cultura, vol. VII, No 19, Quito, BCE.

Farrell, Gilda (ed.) (1989): La investigación económica en el Ecuador, Quito, Instituto Latinoamericano de Investigaciones Sociales (ILDIS).

Hofman, André A. (1993a): Economic development in Latin America in the $20^{\text {th }}$ century. A comparative perspective, Adam Szirmai, Bart van Ark y Dirk Pilat (eds.), Explaining Economic Growth. Essays in Honour of Angus Maddison, Amsterdam, Elsevier/North-Holland.

(1993b): The historical experience: Growth accounting, trabajo presentado a CEPAL/CEDLA Conference on Industrialisation in Smaller Latin American Countries, Amsterdam, julio, mimeo.

(1994): Ecuador: desarrollo económico en el siglo XX; un análisis cuantitativo, Cuestiones económicas, N ${ }^{\circ} 21$, Quito BCE. 
Hurtado, Osvaldo (1988): El poder político en el Ecuador, sexta edición, Quito, Planeta-Letraviva.

Maddison, Angus (1986): Las fases de desarrollo capitalista. Una historia económica cuantitativa, México, D.F., El Colegio de México/Fondo de Cultura Económica.

(1991): Dynamic Forces in Capitalist Development. A Long-Run Comparative View, Oxford, Oxford University Press.

Marchán Romero, Carlos (comp.) (1987): Crisis y cambios de la economía ecuatoriana en los años veinte, Quito, BCE.

Moncada, José (1991): De la independenia al auge exportador, L. Mejía, F. Velasco, J. Moncada, A. Moreno, A. Cueva y R. Báez, Ecuador: pasado y presente, Quito, Editorial "El Duende".

Ramos, Joseph (1986): Neoconservative Economics in the Southern Cone of Latin America, 1973-83, Londres, The Johns Hopkins University Press.
Rodríguez A., Linda (1987): La reforma bancaria de la Revolución Juliana y sus secuelas económicas, 1926-1937, Revista ecuatoriana de historia económica, $\mathrm{N}^{\circ} 2$, Quito, BCE.

Salgado, Germánico (1989): Lo que fuimos, lo que somos, Gilda Farrell (ed.), La investigación económica en el Ecuador, Antología de las ciencias sociales, Quito, ILDIS.

Spurrier Baquerizo, Walter (ed.) (varios números): Análisis semanal, Guayaquil, Ecuador.

Thoumi, Francisco E. (1990): The hidden logic of "irrational" economic policies in Ecuador, Journal of Interamerican Studies and World Affairs, vol. $32 \mathrm{~N}^{\circ} 2$, Estados Unidos, University of Miami.

Vos, Rob (1984): Industrialización, empleo y necesidades básicas en el Ecuador, Quito, ISS/Programa Regional de Empleo para América Latina y el Caribe (PREALC). 